\title{
Social Distance in COVID-19: Drawing the line between protective behavior and stigma manifestation
}

\author{
ARTICLE HISTORY: Received 31 July 2021/Published Online 5 August 2021
}

Social stigma has long been defined by Ervin Goffman as an attribute that it is deeply discrediting and reduces the individual who bears it from a whole and usual person to a tarnished one, unfit to be included into the mainstream society. ${ }^{1}$ As stigma spans time and space and has been documented in other social species such as ants and chimpanzees, one might argue for its adaptive potential. Neuberg et $\mathrm{al}^{2}$ have suggested that humans generate stigmas against threats to effective group functioning, with a notable case being infectious diseases. A similar explanation has been put forward by other researchers who consider stigma to have evolved from disease-avoidance mechanisms. ${ }^{3}$ Hence, it is not surprising that tuberculosis, HIV and leprosy have been surrounded by stigma and discrimination. ${ }^{4,5}$ More recently, people who had survived the 2013-2016 Ebola outbreak tackled social exclusion and unemployment after returning to their neighborhoods. ${ }^{6}$

Nowadays, the global community faces an unprecedented challenge of grappling with the COVID-19 pandemic. From the very outset, social distance measures were introduced in order to contain the spread of the virus, ranging from maintaining 1.5 meters physical distance to strict lockdowns. However, this may easily escalate into stigmatizing and discriminatory behaviours (desired social distance is a proxy of discrimination) against people who have suffered from COVID-19, their relatives and their caregivers, with the United Nations stating that "fear, rumours and stigma" are the key challenges surrounding COVID-19.7 Apart from the psychological distress experienced by the stigmatized individuals, due to anticipated stigma people might start concealing their illness, avoid or delay seeking medical advice or testing until they are seriously ill and be reluctant to collaborate with authorities on tracing contacts. Therefore, timely identifying stigma and addressing it is an integral part of an effective health response to the ongoing pandemic.

In spite of its importance, research on COVID-19 related stigma is scarce. From the perspective of the stigmatized individuals, a study in China ${ }^{8}$ demonstrated that COVID-19 survivors faced heightened levels of overall stigma, social rejection, financial insecurity, internalized shame and social isolation, compared to healthy controls. From the perspective of the general population, a study in US ${ }^{9}$ substantiated low levels of anticipated stigma and stereotype endorsement; however, respondents who anticipated greater stigma were less likely to seek a COVID-19 test. It is therefore clear that the international literature is still on its infancy with respect to COVID-19 related stigma.

In this context, in the First Department of Psychiatry, University of Athens, we conducted a survey on public attitudes to COVID-19 and to mental disorders. The study would inform the design and implementation of anti-stigma initiatives, funded by the Regional Governor of Attica. As physical distancing and social distancing are interwoven, with some researchers and practitioners using the terms interchangeably, and social distancing is also a protective public health measure against COVID-19, we enquired about attitudes and desired social distance from people who had recovered from COVID-19. Nonetheless, it merits noting that evidence from other diseases indicates that stigma may persist even after recovery. ${ }^{10}$ Moreover, rather than describing public attitudes overall, we were more interested in investigating where COVID-19 related stigma stands as compared to the most stigmatizing health condition to date, i.e., severe mental illness. ${ }^{11}$ Interestingly enough, which elements of severe mental illness render it the most stigmatized as compared to other conditions is still speculative: is it the fear of madness? the severity and the type of symptoms? the purported incurability or its chronicity?

In our study, evidence from a convenience sample of 370 residents of Attica indicates that the general population holds more negative attitudes towards people who have recovered from COVID-19 than towards people with mental disorders. Nonetheless, respondents reported lower levels of desired social distance from recovered COVID-19 cases as compared to mental illness cases in social interactions of graded intimacy; however, the difference between the two groups was found to decrease as the level of intimacy decreased as well. In other words, desired social distance from COVID-19 cases is more easily discernible in transient social encounters, like talking to a stranger.

It is therefore clear that social distance is still a public health protective measure rather than a stigma manifestation. For social encounters of greater intimacy, usually a sign of discriminatory behaviours, having recovered from COVID-19 is not a deterrent to interaction. Findings can be explained by the acute (non-chronic) nature of the disease, both in terms of 
symptoms as well as the 10-day period since symptom onset for being contagious. Nonetheless, with emerging evidence substantiating the notion of long COVID-19, defined as the persistence of symptoms for 3 weeks after infection, ${ }^{12}$ this might quickly change. Moreover, with many public health protective measures available, such as the use of mask, diagnostic testing and vaccination, people who become infected are more likely to be blamed for contracting the disease and thus deemed responsible for this, in line with the Attribution Theory. ${ }^{13}$ Specifically, overarching evidence from stigma research in many diseases/conditions indicates that when an illness or a social condition, such as economic disadvantage, is attributed to internal causes, as compared to external, lay people are more likely to hold stigmatizing attitudes. ${ }^{14-16}$ Therefore, as attitudes towards COVID-19 are worse compared to those towards people with mental illness, if tailored anti-stigma action is not undertaken, it is only a matter of time for prejudices to evolve into discriminatory behaviours, with devastating consequences on both the individuals and the course of the pandemic. Concomitantly, as severe mental illness is neither life threatening nor contagious, but COVID-19 is, it is interesting to explore how stigma is related to evolutionary mechanisms favouring adaptability and survival as well as which elements are the drivers of stigma development and establishment. Therefore, comparing and contrasting the stigma surrounding these conditions may shed light on the underpinnings of social stigma and facilitate effective interventions to reduce it and eventually eliminate it.

\author{
Marina Economou \\ Professor of Psychiatry \\ First Department of Psychiatry, Medical School, National and Kapodistrian University of Athens, \\ Eginition Hospital \& University Mental Health, \\ Neuroscience and Precision Medicine Research Institute \\ «Costas Stefanis» (UMHRI), Athens, Greece
}

\section{References}

1. Goffman E. Stigma: Notes on the Management of Spoiled Identity. Prentice Hall, Englewood Cliffs, New Jersey, 1963

2. Neuberg SL, Smith DM, Asher T. Why people stigmatize: Toward a biocultural framework. In: Heatherton TF, Kleck RE, Hebl MR, Hull JG (eds) The Social Psychology of Stigma. Guildford Press, New York, 2000:31-61

3. Park JH, Faulkner J, Schaller M. Evolved disease-avoidance processes and contemporary anti-social behavior: Prejudicial attitudes and avoidance of people with physical disabilities. J NonVerbal Behav 2003, 27:65-87, doi: 10.1023/A:1023910408854

4. Mak WWS, Mo PKH, Cheung RYM, Woo J, Cheung FM, Lee D. Comparative stigma of HIV/AIDS, SARS, and tuberculosis in Hong Kong. Soc Sci Med 2006, 63:1912-1922, doi: 10.1016/j.socscimed.2006.04.016

5. Sermrittirong S, Van Brakel WH. Stigma in leprosy: concepts, causes and determinants. Lepr Rev 2014, 85:36-47, PMID: 24974441

6. Kelly JD, Weiser SD, Wilson B, Cooper JB, Glayweon M, Sneller MC et al. Ebola virus disease-related stigma among survivors declined in Liberia over an 18-month, post-outbreak period: An observational cohort study. PLoS Negl Trop Dis 2019, 13:e0007185, doi: 10.1371/ journal.pntd.0007185

7. United Nations. Coronavirus COVID-19 risk increased to very high but containment still possible. United Nations News: Health 2020 (Cited 14 June 2021). Available from: https://news.un.org/en/story/2020/02/1058331

8. Yuan Y, Zhao YJ, Zhang QE, Zhang L, Cheung T, Jackson T et al. COVID-19 related stigma and its sociodemographic correlates: a comparative study. Global Health 2021, 17:54-62, doi: 10.1186/s12992021-00705-4

9. Earnshaw VA, Brousseau NM, Hill EC, Kalichman SC, Eaton LA, Fox AB. Anticipated stigma, stereotypes, and COVID-19 testing. Stigma Health 2020, 5:390-393, doi: 10.1037/sah0000255

10. van Daalen KR, Cobain M, Franco OH, Chowdhury R. Stigma: the social virus spreading faster than COVID-19. J Epidemiol Community Health 2021, 75:313-314, doi: 10.1136/jech-2020-214436

11. Sartorius N. Stigmatized illnesses and health care. Croat Med J 2007, 48:396-397, PMID: 17589985

12. Greenhalgh T, Knight M, $A^{\prime}$ Court C, Buxton M, Husain L. Management of post-acute covid-19 in primary care. BMJ 2020, 370:3026, doi: 10.1136/ bmj.m3026

13. Weiner B. Judgments of responsibility: A foundation for a theory of social conduct. The Guilford Press, New York, 1995

14. Corrigan P, Markowitz FE, Watson A, Rowan D, Kubiak MA. An attribution model of public discrimination towards persons with mental illness. J Health Soc Behav 2003, 44:162-179, doi: 10.2307/1519806

15. Schuman H, Steeh C, Bobo L, Krysan M. Racial attitudes in America: Trends and interpretations. Harvard University Press, Cambridge, MA, 1985

16. Economou M, Peppou LE, Souliotis K, Lazaratou H, Kontoangelos $\mathrm{K}$, Nikolaidi $\mathrm{S}$ et al. Attitudes to depression and psychiatric medication amid the enduring financial crisis in Attica: Comparison between 2009 and 2014. Int J Soc Psychiatry 2019, 65:479-487, doi: $10.1177 / 0020764019858653$ 